\title{
SUSTENTABILIDADE NA LOGÍSTICA REVERSA: ANÁLISE EMPÍRICA DE MULTIPLOS CASOS
}

Valdecir Cahoni Rodrigues ${ }^{1}$, Alvaro Costa Jardim Neto ${ }^{2}$, Nilmaer Souza da Silva ${ }^{1}$

${ }^{1}$ Universidade do Oeste Paulista - UNOESTE. ${ }^{2}$ Universidade Federal de Mato Grosso do Sul - UFMS

\section{RESUMO}

Este estudo busca, através das preocupações atuais com o meio ambiente e por parte das empresas uma busca pela redução de custos e melhorias em seus processos produtivos, apresentar uma análise qualitativa de múltiplos casos. Os objetos de análise são empresas atuantes no Brasil e possuem alguma interação com o mercado externo, dos mais variados segmentos de mercado tendo sua natureza desde instituições bancárias ao segmento de seguros. Seu referencial teórico busca esclarecer os aspectos de sustentabilidade e logística reversa, além de demonstrar através de ferramental de desenvolvimento sustentável adotado o Triple Botton Line, determinar se esta cadeia logística reversa possa ser considerada sustentável através dos indicadores contido na metodologia e em sua teoria. Acredita-se que este estudo contribua para o meio acadêmico-científico observando a pouca literatura existente na relação dos segmentos estudados e assim gerar a possibilidade de estudos futuros derivado de uma análise mais abrangente destes objetos analisados.

Palavras-chave: Sustentabilidade; Logística Reversa; Triple Bottom Line; Meio Ambiente; Empresas.

\section{INTRODUÇÃO}

As questões ambientais são vistas com mais clareza pelas pessoas e cobrada ainda mais das indústrias para que desenvolvam tecnologias e mecanismos de produção limpa ou com menor dano possível ao meio ambiente. Grande fator para esta preocupação por parte da população são as mudanças climáticas, ainda discutidas se estes são por causa dos danos ambientais gerados pelos tempos, ou até mesmo por uma definição muito utilizada para a sustentabilidade, sendo ela uma maneira de suprir suas necessidades hoje de forma a não prejudicar as gerações futuras, para que possam utilizar dos mesmos fatores de produção e recursos naturais atuais para os próximos que ainda virão.

A legalidade em torno de questões ambientais vem acompanhando esta preocupação e, para alguns, tornando esta observação quanto ao meio ambiente uma obrigação. Várias são elas, mas recentemente uma vem tomando espaço em eventos e discussões sobre áreas afins que é a Lei 12.305 de 02 de Agosto de 2010, denominada PNRS (Politica Nacional de Resíduos Sólidos) que tem por caráter explicativo uma relação de responsabilidade compartilhada entre o poder público, fabricantes, comerciantes e consumidor final no que se refere ao gerenciamento do ciclo de vida 
dos produtos e a destinação final dada para tal, sendo este processo denominado Logística Reversa.

Observando esta preocupação ambiental levantada nos tempos atuais e a adoção de práticas de logística reversa pelas empresas no Brasil, surge uma correlação de forma a originar o problema desta pesquisa que busca, através de alguns indicadores apontados por alguns autores e práticas de algumas empresas no que se refere a logística reversa, determinar assim se a logística reversa pode ser determinada como uma ferramenta sustentável para as empresas. Esta pesquisa possui caráter qualitativo com análise de múltiplos casos e com fontes de dados secundárias para definições a apresentações de dados ora estudados.

\subsection{Objetivo}

O objetivo da pesquisa se delimita na identificação dos fatores de sustentabilidade apresentados em estudos anteriores em algumas organizações pioneiras na aplicação da logística reversa no Brasil. Desta forma, ela se justifica através da razão em demonstrar os indicadores do desenvolvimento sustentável com foco em análise empírica dos processos de logística reversa, sendo este um estudo pouco explorado na literatura nacional.

Algumas questões norteadoras podem ser levantadas podem ser apresentadas para discussão, dando assim direção quanto ao caminho da pesquisa, sendo elas: quais são os indicadores de sustentabilidade cujo indiquem que a logística reversa possa ser denominada sustentável? Como as empresas trabalham com o tema sustentabilidade nas suas práticas de logística reversa? Utilizando destes questionamentos acredita-se que o objetivo desta pesquisa possa ser apresentado de forma clara e concisa.

\section{METODOLOGIA}

Este estudo por sua vez se classifica como sendo uma pesquisa de natureza básica, que tem por definição o objetivo de entender, descrever ou explicar os fenômenos como ocorrem, não sendo reservada e tem como meta a publicação do conhecimento obtido (Netto, 2006). No objeto adotado o estudo tende a demonstrar as práticas de logística reversa utilizadas por algumas empresas com enfoque na sustentabilidade de tais práticas.

Utilizou-se de métodos qualitativos a fim de envolver e examinar as percepções encontradas a fim de obter um melhor entendimento social e humano (Collis, 2005) e, como o estudo busca analisar algumas empresas que adotaram logística reversa em seu processo de 
logística e, selecionados através de caráter não probabilístico, podendo desta forma se denominar o procedimento técnico o estudo de múltiplos casos que por definição de Roesch (2006) trata como um meio poderoso de criar teoria, pois permitem replicação e extensão entre os casos individuais.

Para realizar a análise dos dados através do viés de sustentabilidade na cadeia da logística reversa se fez necessária utilizar dos indicadores levantados por Coral (2002) que apresenta alguns aspectos necessários para se denominar sustentável através do tripé da sustentabilidade, sendo eles:

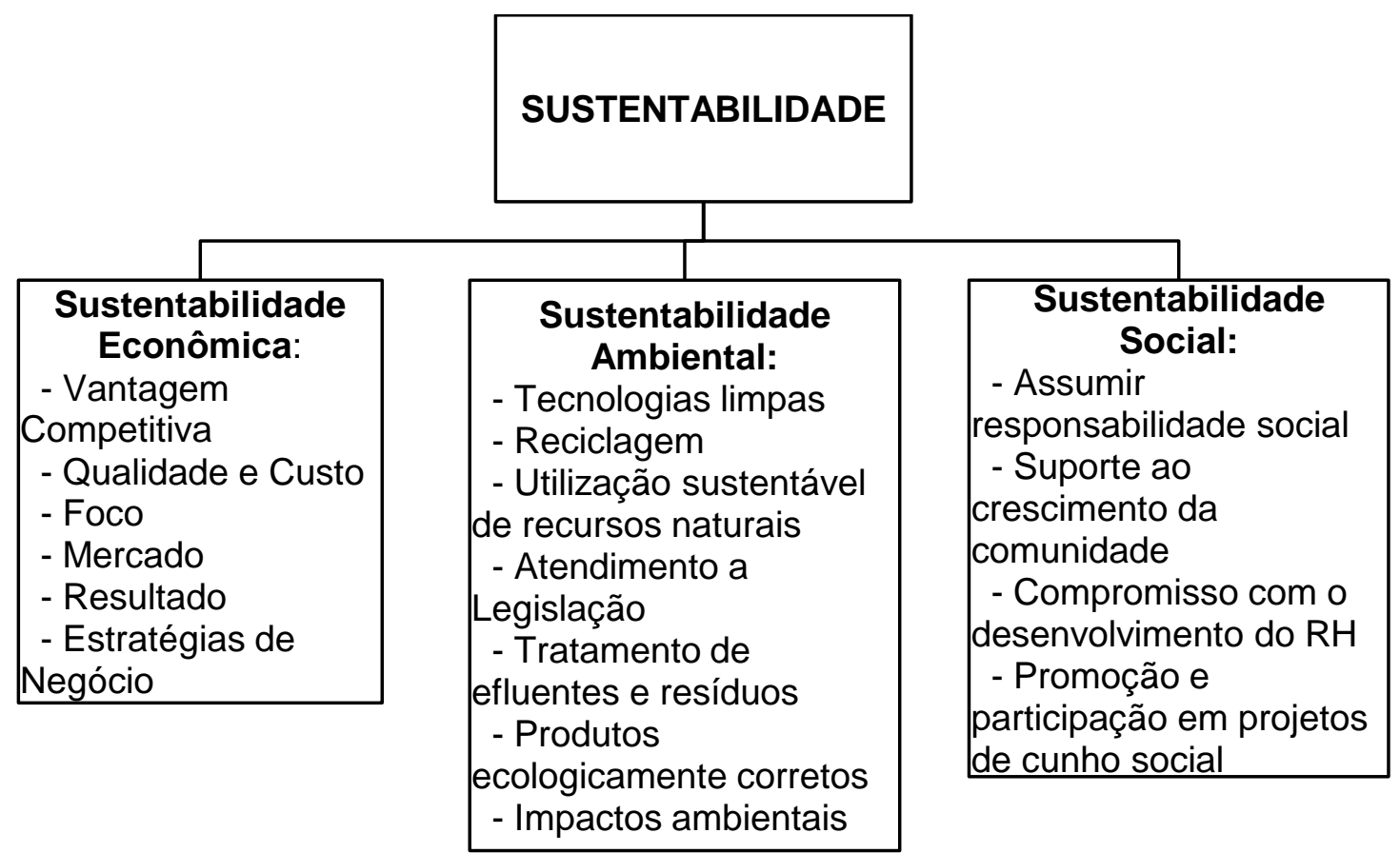

Figura 01. Modelo de Sustentabilidade Empresarial

Fonte: Adaptado de Coral, 2002

Por fim, quanto à técnica de coleta de dados utilizada denomina-se a secundária onde tem como característica a revisão de dados já analisados, como de revistas e sites, empenhando assim confiabilidade e veracidade (Gil, 2002). Característica esta que define os procedimentos técnicos adotados, sendo ele a pesquisa documental que, por sua vez, busca através de documentos de origem secundária, apresentando dados e características sobre o fenômeno estudado (Gil, 2002), no caso, dados coletados a partir de documentos secundários como sites e revistas eletrônicas.

\section{RESULTADOS}


Conforme a figura abaixo serão apresentados algumas empresas atuantes no Brasil que possuam como característica principal práticas de logística reversa como ferramenta do processo logístico e alguns indicadores presentes em seus métodos. As empresas a seguir e seus dados foram apresentados por Ferreira (2011) com as 50 empresas denominadas "do Bem" por praticarem medidas de logística reversa mesmo antes da Lei 12.305 (PNRS) entrar em vigência, no caso, em 2016.

\begin{tabular}{|c|c|c|c|c|}
\hline Energla & Embalagem & Reclclagem & $\begin{array}{l}\text { Gestão } \\
\text { de Resíduos }\end{array}$ & Equipamentos \\
\hline 1-Sabesp & II-Baram & 21-Camargo Corrêa & 31-Walmart & 41-Estre Amblental \\
\hline 2-Mafrig/Seara & 12-Nestle & 22-Vukan & 32-Amber & 42-Braskem \\
\hline 3-McDonald's & 13-Păo de Açû́car & 23-Santander & 33-Spal & 43-Chevron Brasil \\
\hline 4-Solv & 14-Natura & $24-H S Q C$ & 34-Baxter & 44-SulAmerica \\
\hline 5-Embare & 15 - Green Business & 25-Renault & $35-\operatorname{codes} p$ & 45-Light \\
\hline 6-Monsanto & 16-Novelis & 26- Flat & 36- BM\&FBovespa & 46-Itautec \\
\hline 7- Vale & 17-OBoticário & 27-WTorre & 37-WhiteMartins & 47-Cafe Bom Dia \\
\hline 8-Petrobras & 18-Merial Brasil & 28-Denovo & 38 - cyberlar & 48 - Naturalis Brasil \\
\hline 9-Souza Cruz & 19-Bombril & $29-B r a d e s c 0$ & 39 -Levi's & 49-Itâ Unibanco \\
\hline $10-$ Copel & 20-Philips & 30-Banco do Brasil & 40-Arcelor Mittal & 50 - Tetra Pak \\
\hline
\end{tabular}

Figura 02. As 50 Empresas do Bem, divididas em categorias

Fonte: Ferreira (2011)

Através da figura 02 nota-se que as empresas posicionadas entre os primeiros lugares em suas categorias são organizações que atuam em mercado nacional e em alguns casos, internacional. A percepção de indicadores sustentáveis nos processos de logística reversa pode ser definida por algumas como critério de comercialização no mercado exterior onde existe um controle rigoroso e focada nas questões ambientais e sociais.

Observada as empresas classificadas por categoria, segue abaixo a constatação de indicadores de sustentabilidade com enfoque no 3BL apresentado por Coral (2002) em algumas empresas selecionadas para análise: 
Tabela 01: Empresas alocadas no segmento Energia

\begin{tabular}{|c|c|c|c|}
\hline $\begin{array}{c}\text { Empresa } \\
\text { Segmento: Energia }\end{array}$ & Aspectos Econômicos & Aspectos Ambientais & $\begin{array}{l}\text { Aspectos } \\
\text { Sociais }\end{array}$ \\
\hline Sabesp & $\begin{array}{l}\text { - Vantagem } \\
\text { Competitiva } \\
\text { - Mercado } \\
\text { - Estratégia de } \\
\text { Negócios }\end{array}$ & $\begin{array}{l}\text { - Utilização sustentável } \\
\text { dos recursos naturais } \\
\text { - Tratamento de } \\
\text { efluentes e resíduos } \\
\text { - Impactos Ambientais }\end{array}$ & Não Apresentou. \\
\hline McDonald's & $\begin{array}{l}\text { - Qualidade e Custo } \\
\text { - Resultado } \\
\text { - Estratégia de } \\
\text { Negócios }\end{array}$ & $\begin{array}{l}\text { - Tecnologias Limpas } \\
\text { - Reciclagem } \\
\text { - Tratamento de } \\
\text { efluentes e resíduos } \\
\text { - Impactos Ambientais }\end{array}$ & $\begin{array}{l}\text { - Assume } \\
\text { responsabilidade social }\end{array}$ \\
\hline Monsato & $\begin{array}{l}\text { - Estratégia de } \\
\text { Negócios }\end{array}$ & $\begin{array}{l}\text { - Reciclagem } \\
\text { - Tratamento de } \\
\text { efluentes e resíduos } \\
\text { - Produtos } \\
\text { ecologicamente } \\
\text { corretos } \\
\text { - Impactos Ambientais }\end{array}$ & Não Apresentou \\
\hline
\end{tabular}

Fonte: Elaboração própria

$\mathrm{Na}$ tabela 02 apresentará os indicadores encontrados no segmento determinado por Ferreira (2011) como embalagens:

Tabela 02. Empresas alocadas no segmento Embalagens

\begin{tabular}{|c|l|l|l|}
\hline $\begin{array}{c}\text { Empresa } \\
\text { Segmento: } \\
\text { Embalagem }\end{array}$ & \multicolumn{1}{|c|}{$\begin{array}{c}\text { Aspectos } \\
\text { Econômicos }\end{array}$} & \multicolumn{1}{|c|}{ Aspectos Ambientais } & \multicolumn{1}{c|}{$\begin{array}{c}\text { Aspectos } \\
\text { Sociais }\end{array}$} \\
\hline Nestle & $\begin{array}{l}\text { - Estratégia de } \\
\text { Negócios }\end{array}$ & $\begin{array}{l}\text { - Reciclagem } \\
\text { - Impactos Ambientais }\end{array}$ & $\begin{array}{l}\text { - Assume Responsabilidade } \\
\text { Social } \\
\text { - Promoção e Participação em } \\
\text { projetos de cunho social } \\
\text { - Suporte no crescimento da } \\
\text { sociedade }\end{array}$ \\
\hline Pão de Açúcar & - Resultado & $\begin{array}{l}\text { - Utilização sustentável dos } \\
\text { recursos naturais } \\
\text { - Produtos ecologicamente } \\
\text { corretos } \\
\text { - Promoção e Participação em } \\
\text { projetos de cunho social } \\
\text { - Suporte no crescimento da } \\
\text { sociedade }\end{array}$ \\
\hline Natura & $\begin{array}{l}\text { - Estratégia de } \\
\text { Negócios } \\
\text { - Vantagem }\end{array}$ & $\begin{array}{l}\text { - Reciclagem } \\
\text { - Tratamento de efluentes } \\
\text { e resíduos }\end{array}$ & Não Apresentou \\
\hline & \multicolumn{2}{|l}{} \\
\hline
\end{tabular}




\begin{tabular}{|l|l|l|l|}
\hline & Competitiva & $\begin{array}{l}\text { - Produtos ecologicamente } \\
\text { corretos } \\
\text { - Impactos Ambientais }\end{array}$ & \\
\hline
\end{tabular}

Fonte: Elaboração própria

Em sequência, demonstrado na tabela 03, será apresentado a análise quanto ao segmento de Reciclagem e os indicadores constantes neste grupo:

Tabela 03. Empresas alocadas no segmento Reciclagem

\begin{tabular}{|c|c|c|c|}
\hline $\begin{array}{l}\text { Empresa } \\
\text { Segmento: } \\
\text { Reciclagem }\end{array}$ & Aspectos Econômicos & Aspectos Ambientais & $\begin{array}{l}\text { Aspectos } \\
\text { Sociais }\end{array}$ \\
\hline Santander & $\begin{array}{l}\text { - Estratégia de } \\
\text { Negócios }\end{array}$ & $\begin{array}{l}\text { - Utilização sustentável dos } \\
\text { recursos naturais } \\
\text { - Reciclagem } \\
\text { - Tecnologias Limpas } \\
\text { - Impactos Ambientais }\end{array}$ & $\begin{array}{l}\text { - Comportamento com } \\
\text { o desenvolvimento do } \\
\mathrm{RH}\end{array}$ \\
\hline Renault & $\begin{array}{l}\text { - Estratégia de } \\
\text { Negócios } \\
\text { - Vantagem } \\
\text { Competitiva }\end{array}$ & $\begin{array}{l}\text { - Reciclagem } \\
\text { - Tratamento de efluentes e } \\
\text { resíduos } \\
\text { - Produtos ecologicamente } \\
\text { corretos } \\
\text { - Impactos Ambientais }\end{array}$ & Não Apresentou \\
\hline Banco do Brasil & Não Apresentou & $\begin{array}{l}\text { - Reciclagem } \\
\text { - Tratamentos de efluentes e } \\
\text { resíduos } \\
\text { - Impactos Ambientais }\end{array}$ & $\begin{array}{l}\text { - Suporte no } \\
\text { crescimento da } \\
\text { sociedade }\end{array}$ \\
\hline
\end{tabular}

Fonte: Elaboração própria

Na tabela 04 estão em grupo empresas que tem por característica enfoque nos resíduos gerados em seu processo produtivo e de comercialização.

Tabela 04. Empresas alocadas no segmento Gestão de Resíduos

\begin{tabular}{|c|c|c|c|}
\hline $\begin{array}{l}\text { Empresa } \\
\text { Segmento: } \\
\text { Resíduos }\end{array}$ & Aspectos Econômicos & Aspectos Ambientais & $\begin{array}{l}\text { Aspectos } \\
\text { Sociais }\end{array}$ \\
\hline Walmart & - Estratégia de Negócios & $\begin{array}{l}\text { - Reciclagem } \\
\text { - Tratamento de } \\
\text { efluentes e resíduos } \\
\text { - Impactos Ambientais }\end{array}$ & $\begin{array}{l}\text { - Promoção e participação em } \\
\text { projetos de cunho social } \\
\text { - Assumir responsabilidade } \\
\text { social }\end{array}$ \\
\hline Ambev & $\begin{array}{l}\text { - Estratégia de Negócios } \\
\text { - Qualidade e custo } \\
\text { - Resultado }\end{array}$ & $\begin{array}{l}\text { - Reciclagem } \\
\text { - Tratamento de } \\
\text { efluentes e resíduos } \\
\text { - Impactos Ambientais }\end{array}$ & $\begin{array}{l}\text { - Promoção e participação em } \\
\text { projetos de cunho social } \\
\text { - Assumir responsabilidade } \\
\text { social }\end{array}$ \\
\hline Levi's & $\begin{array}{l}\text { - Estratégia de Negócios } \\
\text { - Mercado }\end{array}$ & $\begin{array}{l}\text { - Utilização sustentável } \\
\text { dos recursos naturais } \\
\text { - Tratamento de }\end{array}$ & Não Apresentou \\
\hline
\end{tabular}




\begin{tabular}{|l|l|l|l|}
\hline & & $\begin{array}{l}\text { efluentes e resíduos } \\
\text { - Produtos } \\
\text { ecologicamente corretos }\end{array}$ & \\
\hline
\end{tabular}

Fonte: Elaboração própria

No último agrupamento analisado em pesquisa explanado na tabela 05 encontra-se o segmento de equipamentos, assim determinado anteriormente e seus aspectos do desenvolvimento sustentável.

Tabela 05. Empresas alocadas no segmento Equipamentos

\begin{tabular}{|c|l|l|l|}
\hline $\begin{array}{c}\text { Empresa } \\
\text { Segmento: } \\
\text { Equipamentos }\end{array}$ & Aspectos Econômicos & Aspectos Ambientais & \multicolumn{1}{|c|}{$\begin{array}{c}\text { Aspectos } \\
\text { Sociais }\end{array}$} \\
\hline SulAmérica & $\begin{array}{l}\text { - Estratégia de } \\
\text { Negócios } \\
\text { - Vantagem } \\
\text { Competitiva } \\
\text { - Resultado }\end{array}$ & $\begin{array}{l}\text { - Utilização sustentável } \\
\text { dos recursos naturais } \\
\text { - Produtos } \\
\text { ecologicamente } \\
\text { corretos }\end{array}$ & $\begin{array}{l}\text { - Compromisso com o } \\
\text { desenvolvimento do RH }\end{array}$ \\
\hline \multirow{3}{*}{ Itautec } & $\begin{array}{l}\text { - Resultado } \\
\text { - Estratégia de }\end{array}$ & $\begin{array}{l}\text { - Reciclagem } \\
\text { - Produtos } \\
\text { ecologicamente } \\
\text { corretos } \\
\text { - Impactos Ambientais }\end{array}$ & $\begin{array}{l}\text { - Assumir responsabilidade } \\
\text { social }\end{array}$ \\
\hline Tetra Pak & - Mercado & - Reciclagem & $\begin{array}{l}\text { - Promoção e participação de } \\
\text { projetos de cunho social } \\
\text { - Suporte ao crescimento da } \\
\text { comunidade }\end{array}$ \\
\hline
\end{tabular}

Fonte: Elaboração própria

\section{DISCUSSÃO}

O que foi possível identificar na tabela 01 foi a pouca interação com os aspectos sociais, ou seja, ações que envolvam as comunidades que estejam, mesmo que de forma indireta, próximas as empresas. No aspecto econômico, o indicador mais frequente é o de Estratégias de negócio onde, através destas mudanças nos planos estratégicos geraram ganhos em outros segmentos da sustentabilidade, além de ganhos referente a tais mudanças.

Quanto ao grupo denominado Embalagens e apresentado na tabela 02 foi possível perceber uma miscelânea quanto aos aspectos do 3BL (Triple Botton Line), este fato pode ser determinado pelas diferenças de semento das empresas selecionadas e seus recursos. Um fator nos aspectos ambientais ficou em evidência, sendo ele os Impactos Ambientais onde as empresas analisadas apresentaram preocupações quanto a este fator e possuem planos de redução deste indicador no meio ambiente. 
$\mathrm{Na}$ alocação de objetos de análise apresentados na tabela 03, encontra-se duas empresas do ramo bancário onde, mesmo sendo atuantes do mesmo mercado, possuem quase todas os seus indicadores diferentes, salvo o referente a Impactos ambientais e reciclagem, frequente em todos os componentes do grupo. A preocupação com os impactos ambientais nos tempos atuais deixou de ser uma opção para se tornar um foco de negócios visando as atuais mudanças quanto ao comportamento dos consumidores.

Embora neste segmento determinado como Gestão de resíduos descrito na tabela 04 apareça como indicador frequente os fatores de tratamento de efluentes como apresentado no grupo, estas empresas que atuam em contato direto com o consumidor não demonstram eu seus aspectos econômicos indicadores como o Resultado derivado de seus processos e, com enfoque nas empresas, a Levi's não apresentou em pesquisa características para preencher os aspectos sociais.

Na tabela 05 foi possível identificar a variedade dos setores das empresas atuantes e, como destaque, encontra-se a SulAmérica onde se apresenta no mercado de seguros, ou seja serviços. Esta mesmo diferente das demais empresas alocadas observa sua grande demonstração de indicadores presente em todos as aspectos do 3BL. Sua preocupação com o meio ambiente e seus respectivos ganhos referentes as práticas de sustentabilidade demonstram o indicador Resultado como sendo um fator satisfatório.

\section{CONCLUSÃO}

Visto que a sustentabilidade vem se tornando objeto de estudo frequente no meio acadêmico e científico, empresas e sociedade, mesmo que de forma involuntária, tem agido em prol do meio ambiente e visando assim a sustentabilidade.

Observado esta preocupação nos meios acadêmicos, sociais e empresarias, pode-se perceber através da pesquisa apresentada uma inclinação aos procedimentos logísticos reversos possuírem indicadores que compõem o Tripé da Sustentabilidade. Esta análise e afirmação responde ao objetivo da pesquisa que tinha por objetivo verificar a relação entre os processos logísticos reversos e a sustentabilidade, determinando assim este procedimento como sustentável. Conseguinte busca-se demonstrar através da seleção das empresas para análise que, para um melhor entendimento destes objetos de estudo que possuem logística reversa como processo empresarial, se faz necessária uma análise de outras empresas em seus mais variados mercados atuantes. 
Assim, através desta pesquisa deixa-se uma lacuna para estudos futuros sobre a logística reversa e a sustentabilidade para uma melhor abrangência de estudo visto a limitação de empresas adotadas para pesquisa e análise das mesmas.

\section{REFERENCIAS}

BRASIL, República Federativa do. Lei no 12.305 de 02 de Agosto de 2010. Acesso em 05 jul. 2011. Disponível em: <http://www.planalto.gov.br/ccivil_03/_ato2007-2010/2010/lei/l12305.htm>.

COLLIS, J.; HUSSEY, R. Pesquisa em Administração: um guia prático para alunos de graduação e pós-graduação. 2 ed. Porto Alegre: Bookman, 2005.

CORAL, E. Modelo de planejamento estratégico para a sustentabilidade empresarial. Tese (Doutorado em Engenharia da Produção). Universidade Federal de Santa Catarina, Florianópolis, 2002.

FERREIRA, R. G. As 50 Empresas do Bem. Especial - Empresas do Bem. Revista ISTOÉ Dinheiro. 704 ed. Rio de Janeiro: Editora 3, 2011. Acesso em 10 dez. 2012. Disponível em: <http://www.istoedinheiro.com.br/noticias/53459_AS+50+EMPRESAS+DO+BEM>.

GIL, A. C. Como Elaborar Projetos de Pesquisa. 4 ed. São Paulo. Atlas, 2002.

NETTO, A. A. O. Metodologia da Pesquisa Científica: guia prático para a apresentação de trabalhos acadêmicos. 2ª ed. Florianópolis: Visual Books, 2006.

ROESCH, S. M. A. Projetos de estágio e de pesquisa em administração: guia para estágios, trabalhos de conclusão, dissertações e estudos de caso. 3 ed. São Paulo: Atlas, 2006. 